\title{
Group polarisation among location-based game players: an analysis of use and attitudes towards game slang
}

\author{
Samuli Laato \\ Department of Computing, University of Turku, Turku, Finland and \\ Department of Teacher Education, University of Turku, Turku, Finland \\ Nobufumi Inaba and Mauri Paloheimo \\ Department of Finnish and Finno-Ugric Languages, University of Turku, Turku, \\ Finland, and \\ Teemu Daniel Laajala \\ Department of Mathematics and Statistics, University of Turku, Turku, Finland
}

\begin{abstract}
Purpose - This study investigates how game design, which divides players into static teams, can reinforce group polarisation. The authors study this phenomenon from the perspective of social identity in the context of team-based location-based games, with a focus on game slang.

Design/methodology/approach - The authors performed an exploratory data analysis on an original dataset of $n=242,852$ messages from five communication channels to find differences in game slang adoption between three teams in the location-based augmented reality game Pokémon GO. A divisive word "jym" (i.e. a Finnish slang derivative of the word "gym") was discovered, and players' attitudes towards the word were further probed with a survey $(n=185)$. Finally, selected participants $(n=25)$ were interviewed in person to discover any underlying reasons for the observed polarised attitudes.

Findings - The players' teams were correlated with attitudes towards "jym". Face-to-face interviews revealed association of the word to a particular player subgroup and it being used with improper grammar as reasons for the observed negative attitudes. Conflict over (virtual) territorial resources reinforced the polarisation.

Practical implications - Game design with static teams and inter-team conflict influences players' social and linguistic identity, which subsequently may result in divisive stratification among otherwise cooperative or friendly player-base.

Originality/value - The presented multi-method study connecting linguistic and social stratification is a novel approach to gaining insight on human social interactions, polarisation and group behaviour in the context of location-based games.
\end{abstract}

Keywords Location-based games, Polarisation, Social identity theory, Language, Slang

Paper type Research paper

\footnotetext{
(C) Samuli Laato, Nobufumi Inaba, Mauri Paloheimo and Teemu Daniel Laajala. Published by Emerald Publishing Limited. This article is published under the Creative Commons Attribution (CC BY 4.0) licence. Anyone may reproduce, distribute, translate and create derivative works of this article (for both commercial and non-commercial purposes), subject to full attribution to the original publication and authors. The full terms of this licence may be seen at http://creativecommons.org/licences/by/4.0/ legalcode.

The authors wish to dedicate this work to the memory of Markus Nordblad (1993-2019). Additionally, we would like to thank Mikko Kumpulainen for useful comments regarding the manuscript. Lastly, we are grateful to the Pokémon GO and Ingress player communities who volunteered to participate in the study and assisted in data collection. This research extends the work of Laato et al. (2020a) originally published in the Proceedings of the 53rd Hawaii International Conference on System Sciences.
}

Group polarisation

Received 25 March 2020

Revised 17 August 2020

3 December 2020

23 February 2021

Accepted 27 February 2021 
INTR 31,5

1696

\section{Introduction}

Polarisation poses a threat to our society in the form of escalating conflicts on both individual and group levels (Quershi et al., 2020). Therefore, understanding the underlying mechanisms through which technology can influence group polarisation is important. In this study we approach this research problem from the perspective of social identity (Tajfel, 1974) in the context of location-based games (LBGs) such as Pokémon GO and Ingress. LBGs have recently gained attention for being popular among a wide, intergenerational audience (Saker and Evans, 2021) and being able to scaffold social connectivity between players (Bhattacharya et al., 2019; Vella et al., 2019). Both Ingress and Pokémon GO divide players into static teams which compete over virtual territory (Laato et al., 2021; Söbke et al., 2017). These factors make the games an ideal study context for studying group behaviour and polarisation.

The human social subgroups are influenced by factors such as workplace, hobbies, socioeconomic status and location of residence. Consequently, group polarisation is defined as a characteristic of these subgroups to move towards more extreme viewpoints (Sunstein, 1999). In LBGs as players are given a team with whom they cooperate against other players, an in-group vs out-group setting may emerge (Brewer, 1999). While the teams may guide the formation of players' social circles, it is not clear how strong this effect is and whether it will lead to group polarisation. One way to probe who might belong to a specific subgroup is to look at language use (Ksiazek and Webster, 2008). In this context, a relevant research problem is to explore whether the static teams and inter-group conflict provided by LBGs can be seen at the level of players' language use.

To study these trends, we conducted exploratory research on the differences in language use between three static teams in the LBG Pokémon GO. Altogether, we looked at five asynchronous communication channels across three static teams to identify main differences in use and attitudes of game-related terminology and slang. We further explored these trends by collecting survey data from participants in the researched communication channels, and further investigated interesting findings by interviewing selected candidates. In addition, there was notable overlap between the player communities of Pokémon GO and a related LBG Ingress. For this reason, we also involved Ingress players in the survey and interview stages of our research. Taken together, in this work, we utilise three datasets: (1) chat analysis ( $n=242,852$ messages); (2) a survey $(n=185)$; and (3) face-to-face interviews ( $n=25)$. The rest of this manuscript is structured as follows. First, we present the theoretical lens for this work, which is the social identity theory (Tajfel, 1974) and social influence theory (Kelman, 1958). Subsequently, we look at the literature on social communities in LBGs and language acquisition in gaming communities respectively. We then present our methodology followed by the results, discussion and conclusions.

\section{Background}

\subsection{Theoretical lens: the social identity approach}

Formed in the 1970s, social identity theory explains the role of self-conception and related cognitive processes and social beliefs in an in-group and out-group setting (Hogg, 2016). The origin of the theory can be traced to an experiment by the psychologist Henri Tajfel where he sorted participants into groups based on their performance in a short estimation test. He instructed participants in each group to divide money between all groups and found out that systematically participants favoured their own group, distributing them more money (Tajfel, 1970). These findings have since been reproduced and expanded in several independent studies, even with clearer artificial divides (e.g. Bagby and Rector, 1992; Jetten et al., 1996; Locksley et al., 1980). The social identity approach has been expanded to cover aspects of collaborative behaviour and regulation, including collective behaviour, self-enhancement and 
reducing uncertainty and de-individualisation of out-group members (Hogg, 2016). From an evolutionary psychology perspective, the formation of social identity and in-group thinking has enabled humans to collaborate better, increasing trust and providing satisfaction when aligning with group behaviour (Brewer et al., 2006). It has guarded from trusting possibly hostile groups of humans by generating prejudice against out-group members (Brewer, 1999).

The theory proposes two motivations for out-group discrimination: (1) a desire for cognitive coherence and structure; and (2) a need for positive self-esteem (Abrams and Hogg, 1988). The reasoning behind the first motivation is that for effective collaboration to occur, humans need to be able to make predictions of their group members' behaviour. A shared religion, ideology, culture and habits contribute to increasing the power of these predictions. By contrast, behaviour of perceived out-group members is more difficult to predict, resulting in increased cognitive load and work needed to establish seamless collaboration (Beer et al., 2013). Studies suggest human self-esteem is increased by positive multimodal social feedback (Harris and Orth, 2020), but also via dominating perceived out-group members (Abrams and Hogg, 1988). At the extreme ends of this spectrum, this natural mechanism can produce narcissistic self-evaluation and out-group hate (Cichocka et al., 2017). Overall, the social identity theory is a useful framework for understanding polarisation at the group level (Mackie, 1986). In the online context, the social identity approach has been used to explain video game players' team commitment (Liao et al., 2020) and engagement in social networks (Cheung et al., 2011). Players were found to perceive the existence of group norms in online games, and acceptance of these norms correlated with team commitment (Liao et al., 2020).

Related to social identity theory and often discussed together with it is social influence (Hogg, 2016). The social influence theory was originally introduced in the 1950s by Kelman. He divides social influence into three categories: (1) compliance, (2) identification and (3) internalisation (Cheung et al., 2011; Kelman, 1958). According to Kelman, compliance refers to accepting influence in hopes of a favourable reaction from an individual or group; identification refers to behaviour motivated by the desire to establish or maintain a satisfying relationship to an individual or a group; and internalisation is intrinsically motivated action, where a person accepts influence because they feel content and ideas induced in the proposed action are compelling (Kelman, 1958). Individuals have been found to accept influence from their perceived in-group members and to be motivated to impress them (Hamari and Koivisto, 2015), but reject and oppose influence from out-group members (Hogg, 2016). This finding is important in the context of the current study, as it implies that words associated with a specific team could be collectively rejected by their opponents. In this context, language preference can be used as a proxy to study group polarisation (Ksiazek and Webster, 2008; Peirce, 1995).

\subsection{Social communities in location-based online multiplayer games}

Prior research suggests that computer mediated social networking may amplify group polarisation (Quershi et al., 2020; Sia et al., 2002). Before online gaming became prominent, players would meet physically at, e.g. arcades or LAN (Local Area Network) parties, where computers were connected locally via short network cables and routers or switches (Ackermann, 2012). Arcade halls, LAN-parties and traditional athletic sports require attendance in a pre-specified location and time. By contrast, modern multiplayer online game communities are not limited by the spatial dimension as they are played over the Internet from all over the world (Williams et al., 2006). Multiplayer online gaming is also free from the temporal dimension in the sense that because the games are globally available, they typically have players active at all times.

LBGs such as Ingress and Pokémon GO are a mix between offline and online playing (Leorke, 2018). While the games are always played online, they are also played by walking in 
INTR 31,5

1698 the real world. Thus, they are tied to the physical location of the players (Liberati, 2019). LBGs can be regarded as gamification as they are mixing game elements with the real world (Hamari, 2019), and while playing, the opportunity of non-game related face to face encounters is present. This may boost the reported phenomena that social connections in online games can lead to the establishing of real-world friendship (Schiano et al., 2011). Several LBGs including Pokémon GO, Orna, Walking Dead: Our World, Harry Potter: Wizards Unite, and Ingress provide game mechanics where players gain significant advantage from cooperating, subtly pushing players to interacting with others (Riar et al., 2020). The game design, available goals and game mechanics in these games have major influence on what kinds of social interactions and social phenomena arise during play (Bhattacharya et al., 2019; Morschheuser et al., 2017; Riar et al., 2020).

From a social standpoint, LBGs are unique among other multiplayer online games in that players do not retain anonymity. Despite players having pseudonyms in-game, LBG players can be seen by others walking and playing in the real world, which removes the online disinhibition effect (Suler, 2004). This can reduce the likelihood for cyberbullying and toxic behaviour, which present rampant problems in multiple fully online multiplayer games (Blackburn and Kwak, 2014; Kordyaka et al., 2019; Kwak et al., 2015). The presence of social regulations on behaviour might contribute to more harmonious interaction and better understanding between players (Vella et al., 2019). In fact, social identity theory (Hogg, 2016) and in particular the contact hypothesis originally proposed by Allport (1954) suggests that simply establishing discourse with out-group members may curb prejudiced opinions and help people feel empathy towards each other.

As playing in LBGs is tied to a physical location, players are likely to share interests, habits and culture that is associated with geographical location. This can make social interaction more harmonious due to players sharing common interests (Wright and Jacobs, 1994). While the positive effects of LBGs on social connectivity (Vella et al., 2019), weintentions and altruism (Riar et al., 2020) have been studied, the flip side of this phenomenon which is the polarising effect of the static teams is yet to be explored.

\subsection{Language acquisition in gaming communities}

Language use and preference can be used as predictors of social behaviour and group identity (Ksiazek and Webster, 2008). This idea is strongly present in the field of linguistic ideology, which seeks to understand social and cultural systems based on language use and preference (Irvine et al., 2009; Rumsey, 1990). As games are worlds of their own, slang terms and new words emerge among gaming communities. Examples of game-related words and phrases which have reached global online adoption include "get rekt", "N00b", "1337" or "133t" (Blackburn and Kwak, 2014). These words can originate in written form and then spread to spoken language, or alternatively be first introduced to spoken language. In online gaming, the mechanisms for adopting such words are linked to the player communities, and the spread is accelerated, for example, when popular gaming personalities start using the words. This speaks of the social nature of language and the role of social hierarchies in language use (Irvine et al., 2009; Rumsey, 1990). New game-related words and phrases have reportedly spread via the chat on the popular live game streaming platform Twitch.tv (Olejniczak, 2015) as well as more subtly between players in online chat groups. What is interesting from the perspective of the current study, is that slang-terms used by players of opposing teams can receive negative connotations giving birth to negative attitudes towards the words and their users (Drake, 1980; Eble, 1996).

The processes through which potentially polarising language or slang emerges can be related to the natural evolution of language. Language develops organically as people balance the cost and effectiveness of their word choices (Ojutkangas et al., 2009). For example, 
if a particular word is tedious to pronounce or very long, players are prone to find replacements for it (Ojutkangas et al., 2009). Multiplayer games set a unique challenge to communities of non-English speakers when a translation of the game is not available. For example, in Finland, local Ingress and Pokémon GO communities use predominantly Finnish when discussing game related phenomena. As there is no Finnish localisation of the game, players casually mix English words into their sentences, which otherwise follow Finnish grammar. The Finnish language belongs to the agglutinative languages (Löfberg et al., 2003), and as foreign words might be difficult to pronounce, players often invent their own slang (Coleman, 2012). These slang terms can emerge in a single team, but never reach acceptance of the whole player base (Coleman, 2012).

One way to study language preference is to look at the active vocabulary of people. Actively used vocabulary has been used as a predictor of adopted social identity. For example, parents can feel a sense of loss when hearing their children use (slang) words that sound unfamiliar to them (Ochs, 1993). However, in addition to vocabulary, manner of speaking, intonation and other aspects of communication may also be indicators of social identity. As an example, individuals have been found to use abstract and general language when describing positive behaviour and more concrete and specific language when describing negative behaviour of their in-group members (Porter et al., 2016). This type of language use implicitly suggests that the positive behaviour is recurring and omnipresent whereas the negative behaviour is only something that has occurred on some very specific instances. With regards to an out-group, the language use is reversed (Porter et al., 2016). These implicit language patterns serve to protect the integrity of an individuals' in-group while giving rise to prejudice towards the perceived out-group members. Following our theoretical approach, another mechanism how language can predict social identity, especially in the context of multiplayer online games, is to look at players' attitudes towards game slang associated with opposing team members (Irvine et al., 2009; Ksiazek and Webster, 2008). However, before such analysis can be done, potentially polarising slang terms need to be identified.

\section{Empirical study}

\subsection{Case games}

For the empirical part of this study we focus on active player communities in two games: Ingress and Pokémon GO. The games were selected due to being the two most popular LBGs measured by the number of active installs (Laato et al., 2020b). Both games are available for Android and iOS and are developed by the same company, Niantic. The games share the same database of geographical points of interest (PoIs) but differ in game mechanics (Laato et al., 2019). As players in Ingress and Pokémon GO are split into static teams who are competing against each other over territorial resources, the games are suitable candidates for studying polarisation in our theoretical setting.

3.1.1 Pokémon GO player communities. Pokémon GO has accumulated a large body of academic research due to its massive popularity. Social interaction is currently promoted by Pokémon GO gameplay decisions in several ways. The game includes raid bosses, which are stronger in-game challenges that require players to unite, typically beyond team boundaries (Bhattacharya et al., 2019). Coordinating raids and sharing information about their locations is common practice in Pokémon GO communities (Bhattacharya et al., 2019). In addition to raids, Pokémon GO also features gameplay elements that require physical proximity of players, such as trading pokémon (Niantic, 2019). In addition, players can spend time playing together with their real-world friends regardless of team allegiance, as there are no negative repercussions from playing with friends (Paasovaara et al., 2017). 
INTR 31,5
Pokémon GO has three teams: Instinct, Mystic and Valor, and players can only belong to a single team (Vella et al., 2019). The team choice is otherwise permanent but can be changed once per annum in exchange for in-game currency. As team members benefit from playing with each other and often have their own exclusive communication channels, players end up more frequently bonding with members of their initially chosen team. Pokémon GO has been observed to have a diverse player base in regard to gender and age (Potts and Yee, 2019; Vaterlaus et al., 2019), breaking the previously observed trend that young men compose a vast majority of video game player-base (Burgess et al., 2012). The opportunity to interact with players who may come from a different socioeconomic, ethnic and age-related backgrounds, can be seen as an enriching social experience, which can have a positive impact on players' attitudes and understanding towards each other (Kircher and Fox, 2019).

3.1.2 Ingress player communities. Currently, there are two teams in Ingress, referred to as factions: Enlightened and Resistance. Players choose a faction at the very beginning and faction change is difficult, hence people tend to adopt their faction's social context and befriend players from the same faction (Morschheuser et al., 2017; Tokgöz and Polat, 2018). Cooperating with players from the opposing faction is forbidden in Ingress rules, which reinforces a division between the teams. The factions typically have their own exclusive chats where only members of the same team are allowed. Thus, the design of Ingress not only divides players into two teams (Sheng, 2013), but also influences the social relationships of players.

The problem of group polarisation due to the two Ingress factions has been loosely addressed by in-game social events such as First Saturdays, XM Anomalies and Mission Days, where players from both teams can meet each other in a friendly setting (Fragoso and Reis, 2016; Söbke et al., 2017). In addition, independent organisers have constructed, for example, outdoor museums using Ingress as a backbone, which are aimed at players of both factions (Shirai et al., 2015). Regardless, Ingress players appear enthusiastic about the social dimension of the game and acknowledge that the game requires competition between the factions as the gameplay becomes stagnant if one side is dominant (Riar et al., 2020; Söbke et al., 2017). In fact, previous studies highlight the positive effects Ingress has on team spirit, joint commitment and attitudes towards cooperation and even altruism (Morschheuser et al., 2017; Riar et al., 2020).

\subsection{Study overview}

Our overall research design is depicted in Figure 1. First, an exploratory search was utilised in five communication channels to identify potential candidate slang words for a closer analysis (Figure 1a). For this purpose, the largest team chat of each Pokémon GO team as well as two additional chats were studied. Comprehensive inspection of game slang use provides information regarding team influence and also brings clarity to the underlying social structures among players. A potentially polarising word "jym" i.e. gym was manually identified and then investigated. Its use was then sorted into two categories: (1) being the subject of discussion; or (2) being used casually during conversations (Figure 1b). Consequently, a self-developed eight-item survey was sent to the observed chats in order to obtain information of players' attitude towards the particular slang term (Figure 1c). Finally, selected players were interviewed face to face in a non-formal fashion by the authors, asking them about their perception and opinions towards the slang-word "jym" and inquiring how they formed their attitude towards the word (Figure 1d). In summary, method-wise this study is divided into the following three parts:

(1) Aim: Identify differences in language use between teams. 
Method: Scan player communities and team exclusive chats for slang words and their frequency. Sort appearance of interesting words based on whether they are used naturally or if they were the topic of a discussion. (Figure 1a and 1b)

(2) Aim: Investigate and quantify statistical significance of use and attitudes towards identified slang words.

Method: Survey players in the same chats via a questionnaire focused on opinions and attitudes towards non-universal slang terms. (Figure 1c)

(3) Aim: Explain the observed relationships.

Method: Face to face interviews with select participants asking their personal reasons for using or not using the specified words as well as how they formed the reported attitudes towards the words. (Figure 1d)

\subsection{Scanning for differences in language use among Pokémon GO and ingress communities}

Initial observations of Pokémon GO and Ingress communities from South-Western Finland during 2016-2019 resulted in identifying several slang terms related to the games (Figure 1a and b). In Ingress, these included words based on previous names of Ingress items. For example, Aegis shield was called "axa" (due to an old sponsorship deal) and the CircleK and Lawson power cubes were called "sponssicube", which roughly translates into "sponsorship cube”. In Pokémon GO, slang words were discovered for gyms, Pokémon (e.g. “monni”, a word for a fish which rhymes with the latter part of the word pokémon) or activities, i.e. "sahata", a verb which literally translates to "sawing", but which was used to describe taking down gyms. Primary focus at this stage was to find slang terms which were actively used by certain subgroups of players, but not by all players.

3.3.1 Chat data search. Five Pokémon GO chats in South-Western Finland were extracted and anonymised for further data analysis (Figure 1a). First, the most popular chat of each one of the three Pokémon GO teams, Instinct (99,798 messages), Mystic (90,711 messages) and Valor (7,931 messages) were selected. Joining these chats was open for everyone under the

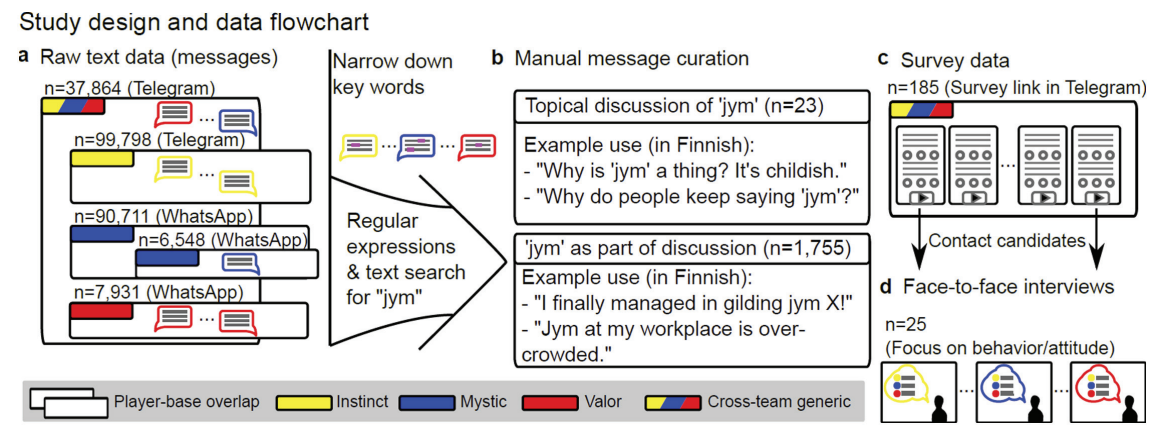

Note(s): (a) Primary exploratory data were derived directly from intra- and inter-team communication channels among Pokemon GO players, which was then (b) Subjected to aromatic and manual searches, which resulted in the word "jym" emerging as a divisive agent. Afterwards discussion surround "jym" was manually read to establish whether the word was being discussed or used naturally (c) A survey was posted to the same channels with a focus on the term "jym" and finally, (d) Willing participants were interviewed face to face by the authors, further exploring reasons and background regarding attitudes towards the slang terms

Figure 1. Overall research design flowchart 
INTR 31,5

1702

condition that they belonged to the specified team. Additionally, a chat including members from all three teams (37,864 messages) and a special chat inside Team Mystic 6,548 messages) were included. The data from the chat groups was from the following periods: Case 1 Instinct (September 2016-April 2019), Case 2 Mystic (August 2017-March 2019), Case 3 Valor (July 2018-July 2019), Case 4 cross-team chat of all three teams (October 2017-January 2019), Case 5 smaller Mystic chat (May 2018-March 2019). The case 5 chat was selected post hoc as it represented early adopters of the "jym"-word. Access to Ingress chats could not be obtained due to the chats being perceived non-public by their members. Information regarding the collected chat data is displayed in Table 1.

Almost all discussion in the chats was in Finnish, with minor exceptions of conversation in other languages of which the most popular one was English. The non-Finnish messages were also included in the data analysis. The moderators of the chat channels gave permission to mine the data for linguistic trends. The data was carefully handled by the researchers and no external copies were ever stored outside the University servers. As the chat channels were publicly accessible to members of the specific team in the given geographical location, and no individual members could be identified, it was decided to be ethical to conduct an anonymous scan of slang words used in the chats. Research permission was asked by participants during a follow-up survey, however, not all members who had been posting messages to the chats during 2016-2019 could be reached in this manner. Therefore, no demographic data could be reported from the chat channels, only frequencies of the use of chosen slang words.

3.3.2 Chat data analysis. First, the frequency of the usage of the words for "pokémon", "gyms" and "raids" were searched for in the chats in order to detect any differences in the use of game-terminology. This part was done automatically. Following the findings, the most interesting word (which turned out to be "jym", a slang word for "gym") and its use were explored further by reading discussion surrounding the word and classifying the use of the word into natural use and discussing the use of the word (Figure 1b). "Jym" was selected as the top candidate for closer analysis, as it appeared as a clearly divisive word both in attitude and active usage between the studied teams. This part was manually conducted by the second author.

\subsection{Survey and statistical methodology}

Following the results of the chat analysis, players' perceptions towards the divisive term "jym" were probed further with a survey. "Jym" was also known among Ingress players, firstly because many of them also played Pokémon GO, and secondly because some players had submitted new portal candidates to the Niantic PoI database (Laato et al., 2019; Tregel et al., 2017), containing the slang-word "jym". This exposed Ingress players to terminology that was alien to their game. Due to overlap between the local Pokémon GO and Ingress player communities in terms of several players playing both games, Ingress players' opinions were considered as supplementary material in the survey. What made Ingress relevant to the study is that while Pokémon GO players had first-hand experience of "jym" (the term originated as game slang among Pokémon GO players), Ingress players had no meaning for

Table 1. Chat messages collected for analysis

\begin{tabular}{lccl}
\hline Chat type & Number of messages & Collection time & Medium \\
\hline Case 1 Instinct & 99,798 & $9 / 21 / 2016-4 / 29 / 2019$ & Telegram \\
Case 2 Mystic & 90,711 & $8 / 14 / 2017-3 / 27 / 2019$ & WhatsApp \\
Case 3 Valor & 7,931 & $6 / 20 / 2018-6 / 10 / 2019$ & WhatsApp \\
Case 4 All teams & 37,864 & $10 / 18 / 2017-1 / 6 / 2019$ & Telegram \\
Case 5 Mystic2 & 6,548 & $5 / 4 / 2018-3 / 27 / 2019$ & WhatsApp \\
\hline
\end{tabular}


the word in their playing context. In fact, they only knew about the word through portal candidates named "jym" as well as either playing Pokémon GO themselves or having connections to players who played Pokémon GO.

3.4.1 Survey description. The online questionnaire probing players' attitudes and use of the word "jym" was sent to Pokémon GO and Ingress players in South-Western Finland on July 2019. Players who replied to the survey, but who did not give permission to use their answers in research, were excluded. The questionnaire was open for one day and distributed directly to the chats analysed in the current study, and contained the following questions:

(1) Are you familiar with the term "jym"? (yes, no)

(2) Are you actively using the term "jym" yourself? (yes, no, sometimes)

(3) In case you do not say "jym", what do you say instead? (open question)

(4) How do you feel about the term "jym"? (positive, neutral, negative)

(5) State your team in Pokémon GO (Instinct, Mystic, Valor, I do not play Pokémon GO)

(6) State your team in Ingress (Enlightened, Resistance, I do not play Ingress)

(7) How old are you? (Below 18, 18-25, 26-40, 41-60, over 60)

(8) State your username in Ingress and Pokémon GO. (open text field)

3.4.2 Data analysis. The statistical analyses and presentation of the survey data were conducted in the $\mathrm{R}$ statistical software version 3.6.1 (R Core Team, 2020). In addition to the base installation, extending $R$-packages corrplot (v0.84), ComplexHeatmap (v2.0.0) (Gu et al., 2016), hamlet (v0.9.6), and foreign (v0.8-71) were used. Survey data was mainly trinary coded with value -1 indicating a negative response, value 0 indicating a neutral response or a missing value, and value +1 indicating a positive response. The conducted hierarchical clustering accompanying the rows and columns of the heatmaps was done using complete linkage coupled with the Euclidean distance. Default parameters were used for all plots and statistical analyses, including the Pearson correlation matrix plot for associations between interesting variables from the survey. Further, tabulated data for associations was subjected to statistical inference using Fisher's Exact Test coupled with Benjamini-Hochberg multiple testing corrections.

\subsection{Interviews with players and additional data}

Participants who had extreme replies in the survey and selected participants who reported a negative attitude towards "jym" were invited for a face to face interview, or asked to give a comment online, for further investigation $(n=25)$. These interviews were carried out in a nonformal fashion by the first three authors. All collected data was in Finnish but was translated into English by the first author in order to display exemplary quotes. All interviewed participants gave consent to use their replies for research.

\section{Results}

\subsection{Chat analysis results}

Frequency of slang terms for pokémon, gyms and raids were looked for in the chats. The words were observed in their basic form (including conjugations) and as compound words. In the case of words for pokémon and raids, no major differences between teams were observed. The frequency of gym slang terms in the five chats is displayed in Table 2. "Torni" means a tower in English, and the word can be traced back to 2016-2017 when the graphical layout of gyms resembled that of a tower. "Sali" can be considered the most accurate translation for 


\begin{tabular}{|c|c|c|c|c|c|c|c|c|c|}
\hline $\begin{array}{l}\text { INTR } \\
31,5\end{array}$ & & Gym & $\begin{array}{l}\text { Compound } \\
\text { word }\end{array}$ & Sali & $\begin{array}{l}\text { Compound } \\
\text { word }\end{array}$ & Jym & $\begin{array}{l}\text { Compound } \\
\text { word }\end{array}$ & Torni & $\begin{array}{c}\text { Compound } \\
\text { word }\end{array}$ \\
\hline & $\begin{array}{l}\text { Case } 1 \\
\text { Mystic }\end{array}$ & 1173 & 53 & 1675 & 58 & 393 & 4 & 16 & 0 \\
\hline & $\begin{array}{l}\text { Case } 2 \\
\text { Valor }\end{array}$ & 36 & 1 & 173 & 3 & 11 & 0 & 0 & 0 \\
\hline 1704 & Case 3 & 39 & 3 & 124 & 8 & 453 & 22 & 0 & 0 \\
\hline $\begin{array}{l}\text { Table } 2 . \\
\text { Comparing "jym" }\end{array}$ & $\begin{array}{l}\text { Case } 4 \text { All } \\
\text { teams }\end{array}$ & 370 & 9 & 677 & 13 & 536 & 4 & 11 & 0 \\
\hline $\begin{array}{l}\text { usage with } \\
\text { alternative terms }\end{array}$ & $\begin{array}{l}\text { Case } 5 \\
\text { Mystic } 2\end{array}$ & 113 & 9 & 72 & 2 & 393 & 39 & 0 & 0 \\
\hline
\end{tabular}

"gym" in Finnish. "Jym" is not a Finnish word, but it arguably fits spoken Finnish language better than "gym", as the letter " $"$ " is easier for Finns to pronounce and its tone closely resembles that of the letter " $g$ ". However, "jym" was often used in written chats without conjugation, breaking the rules of Finnish grammar. What is especially interesting in this data is that "jym" was used actively in all other chats except that of team Valor.

All instances of "jym"-use were automatically searched ( $n=1,469$ messages). All messages containing the word were manually read including the context. This allowed categorising the usage of "jym" into natural (i.e. adopted to use as part of language) and being the topic of discussion (i.e. commented on or criticised). The results are displayed in Table 3. In proportion to the overall number of messages containing "jym", members of team Valor were overwhelmingly discussing the term instead of actively using it. There were 501 messages in the common chat concerning the word and also the most instances $(n=10)$ when the word was discussed as a subject. The word was proportionally the most used in the smaller Mystic chat where the term was used 393 times but never discussed as a subject. This might be explained by that all participants in that chat (1) knew each other; (2) could be considered highly active players; (3) were also actively interacting outside the chat in both online and offline contexts; and (4) had been playing the game for longer than two years. These four factors indicate that the team members had time to bond and develop a social subgroup with their own mannerisms and group behaviour. This would have led the players to develop a social identity. Outward expression of such identity (i.e. the use of "jym") was discussed by team Valor, but never adapted in use, showcasing that a stratification of players into social subgroups could be seen already at this stage.

Table 3.

Appearance of "jym" in five analysed Pokémon GO chats

\begin{tabular}{lccccc}
\hline & $\begin{array}{c}N \text { messages } \\
\text { containing jym }\end{array}$ & $\begin{array}{c}N \text { times jym } \\
\text { mentioned }\end{array}$ & $\begin{array}{c}\text { First } \\
\text { appeared }\end{array}$ & $\begin{array}{c}\text { Used } \\
\text { naturally }\end{array}$ & $\begin{array}{c}\text { Discussed as a } \\
\text { subject }\end{array}$ \\
\hline $\begin{array}{l}\text { Case 1 } \\
\text { Mystic }\end{array}$ & 245 & 393 & $10 / 25 / 2017$ & 392 & 1 \\
Case 2 Valor & 10 & 11 & $1 / 8 / 2019$ & 5 & 6 \\
Case 3 & 366 & 453 & $3 / 10 / 2018$ & 443 & 6 \\
$\begin{array}{l}\text { Instinct } \\
\text { Case 4 All }\end{array}$ & 501 & 536 & $3 / 10 / 2018$ & 522 & 10 \\
teams & 347 & 393 & $5 / 4 / 2018$ & 393 & 0 \\
Case 5 & & & & & \\
Mystic 2 & & & & &
\end{tabular}




\subsection{Survey results}

Following the exploratory chat search we sent a survey to the chat participants. The survey received 192 responses during the one day it was open. Out of all respondents, $n=185$ gave consent to use their answers for research purposes. The participant data including age and team distributions are displayed in Table 4.

Heatmap in Figure 2 presents all the survey data and illustrates the main trends in it, with the rows and columns rearranged based on hierarchical clustering. As can be seen from the column annotations, Pokémon GO players from team Instinct (yellow) were both most positive in their attitude towards "jym" and were, as expected, consequently its most prominent users. By contrast, players from team Valor (red) were the opposite (yellow Instinct aggregating to the left, while red Valor aggregated to the right side of the column annotations). In connection with the lower portion of the data, players who had a positive attitude towards the slang word had a tendency to not use any other synonyms, while players exhibiting either a neutral or a negative attitude were using natural alternatives such as the literal Finnish translation ("sali") for its English equivalent ("gym"). Other words such as "portaali" (Finnish for "portal") or "torni” ("tower") were much more scarcely used. Some free

\section{Age}

below 18

$18-25$

$26-40$

$41-60$

over 60

missing value

Pokémon GO team

Valor

Instinct

Mystic

I do not play Pokémon GO

Ingress faction

Resistance

Enlightened

I do not play Ingress
Group

polarisation

1705

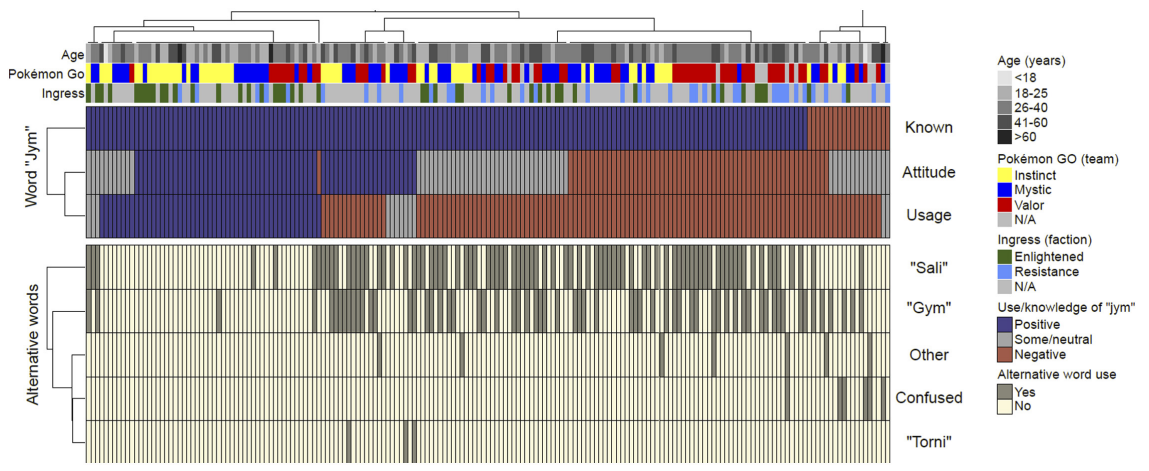

Figure 2.

Heatmap depicting a broad overview to the survey data for players' attitude and usage for the slang word "jym" (upper portion) as well as reporting the usage of alternate words (lower portion). These alternatives were especially prominent in cases where opinion or awareness of the slang term was negative 
INTR 31,5

1706
Figure 3.

(left panel) Boxplot between "jym" word usage frequency and the quantiles within age groups, with jittered $x$-axis for purposes of visualisation; (right panel) Pearson correlation matrix plot for variables. Direction of the correlation is shown ranging from red (negative) to positive (blue). Grey boxes: mutually exclusive player groups; crossed-out boxes: statistically insignificant association

text field answers were categorised as "confused" $(n=6)$, which was associated with the survey participant not being familiar with "jym" prior to answering the survey.

In the survey, $26 \%$ of respondents $(n=51)$ replied they were actively using "jym", and $6.5 \%(n=12)$ answered that they sometimes used the word. The highest ratio of players using "jym" inside each team was in Team Instinct $(43 \%, n=22)$, followed by Team Mystic $(28 \%, n=18)$ and Team Valor $(19 \%, n=11)$. As expected, a trend was observed tightly connecting positive attitudes towards active use of "jym". Team Valor, who were recorded to have the least players using the word, also had the highest number of players with a negative attitude towards the word $(50 \%, n=29)$. Mystic players were the most neutral with $25 \%$ of players stating a negative attitude towards the word and $38 \%$ of players responding they were indifferent towards the word. Team Instinct was the leading "jym" term supporter with only $20 \%$ of players having a negative attitude towards the word.

We further systematically analysed associations between key variables that were extracted from the survey data. Figure 3 left panel shows that perhaps counter-intuitively, there was no statistically significant association between the ordinal age category of the player and the frequency of usage of "jym" among survey participants. A systematic exploration for associations via a correlation matrix plot (Figure 3 right panel) identified interesting trends in the data; firstly, as expected, having a positive attitude towards the word was highly associated with increased likelihood of using the word, while awareness of the existence of the slang word slightly increased likelihood of using it. Team Instinct showed both positive association with the attitude and usage of the slang term, while belonging to the team Valor had the opposite effect. In our study, the participants from the Ingress faction Resistance were associated with a slightly elevated age, and displayed a small but significant negative tendency to like and use the slang word. These findings were concordant with the visual inspection of the whole dataset readily presented in Figure 2.

In order to conduct thorough statistical testing of associations in our data, we tested associations in tabulated data using Fisher's Exact Test. Full results from this testing are shown in Supplementary. This analysis showed a statistically significant association between players' team in Pokémon GO and attitude towards "jym" $(\phi<0.05)$, while the association between Ingress faction and attitude towards the word was statistically not significant $(\phi=0.09)$. This lack of notable association may be partially explained by the

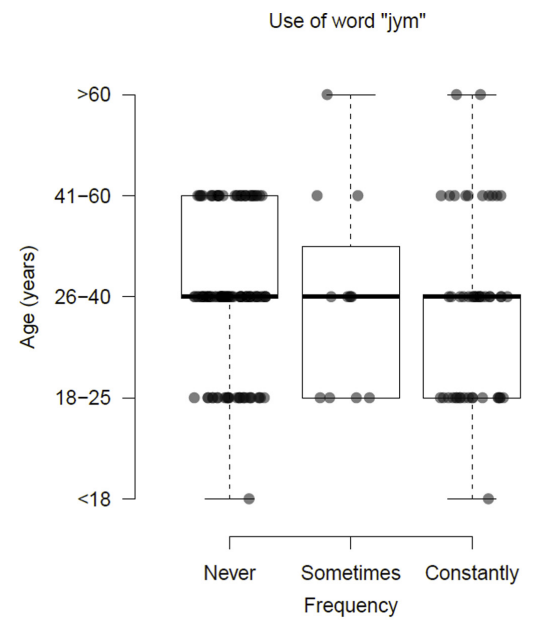

(a)

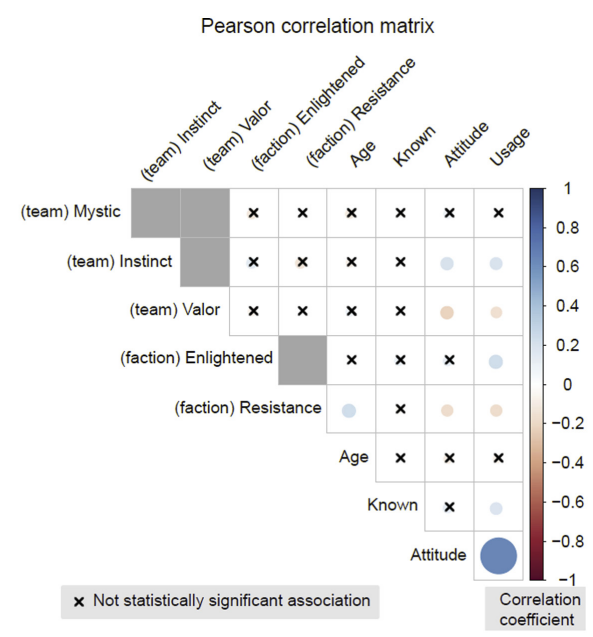

(b) 
relatively smaller number of Ingress players replying to the survey, resulting in lower statistical power. In addition, we investigated whether existing social connections had affected Pokémon GO players' transition to Ingress and the selection of their faction and vice versa. However, the association between Pokémon GO team and Ingress faction turned out to be statistically insignificant $(\phi=0.10)$. In addition, a highly significant correlation between using "jym" and having a positive attitude towards it was also reported $(\phi<0.001)$. This clear effect was consistent with our previous observations of the attitude and usage towards the word in the chat messages. Altogether, the associations identified using Fisher's Exact Test for tabulated data (available in Supplementary) were concordant with the statistically significant correlations observed in Figure 3 right panel.

Out of the Ingress players who respondent to the survey, $50 \%$ of team Resistance perceived "jym" negatively, while only $23 \%$ of team Enlightened did. Team Resistance also had fewer players with a neutral attitude towards the word compared to Enlightened. All Ingress players with a positive attitude towards "jym" also played Pokémon GO. Out of those Ingress players who did not actively play Pokémon GO, 55\% had a negative attitude towards the word, $45 \%$ had a neutral stance, and none reported having a positive attitude towards the word. Out of the 84 Ingress players who responded to the questionnaire, only 11 reported to never have played Pokémon GO. From the nine Resistance faction players who reported a positive attitude towards "jym”, all played Pokémon GO (2 Instinct, 5 Mystic, and 2 Valor); similarly, all 18 Enlightened players who reported positive attitudes towards "jym", all were Pokémon GO players (8 Instinct, 5 Mystic, and 5 Valor). From the 10 Enlightened players who reported negative attitude towards "jym”, 7 played Pokémon GO (2 Instinct, 1 Mystic, and 4 Valor); out of the 16 Resistance players who reported negative attitude towards "jym, 16 played Pokémon GO (1 Instinct, 6 Mystic, and 9 Valor). These findings indicate that positive attitudes towards the word in Ingress circles came from playing Pokémon GO and having relationships with Pokémon GO players.

\subsection{Interviews with players and explaining the negative attitudes towards "jym"}

4.3.1 "Jym" was associated with a specific group of players. Interviews with members of the teams (Mystic, Valor and Resistance) that had the most negative attitudes towards "jym", showed that the word was heavily associated with a certain group of active players from team Mystic. From here some players adopted "jym" into their common parlance while others rejected the word as evident from the chat and survey analyses. However, the word never lost its initial association to certain Mystic players, with whom seven interviewed team Valor members had previously had conflict with. One interviewed participant explains:

It's a word used by elitist blue and yellow players who have spread it to their own groups. In the reds some have also adopted it.

Research on social identity and influence suggests that associated language may lead to forming prejudice towards its users (Maddox et al., 2012; Uhlmann et al., 2006). In our study, context words used by disliked players are likely to have caused lasting negative connotations. Therefore, newer players who adopted the word to use but had no prior personal conflicts, were prone to be seen in a negative light.

4.3.2 "Jym" violates the Finnish grammar. The second reason found for the negative attitudes towards the "jym" term, was that it was used in a way which violated the rules of Finnish grammar. This was explained by one interviewed player as follows:

JYM gets an immediate dislike-reaction from me and painfully reminds me of language that some people used that disparaged the Finnish language. 
INTR 31,5

Poor grammar is associated with incompetence, and for many employers it can be an indication of poor work ethics and quality of work (Wiens, 2012). The Finnish language belongs to the agglutinative languages meaning it is customary to conjugate words (Löfberg et al., 2003). However, with the word "jym" and similarly with the word "raid", this was often not done as demonstrated in the analysed chat logs. The Pokémon GO team that had the most negative attitudes towards "jym" (team Valor) also almost exclusively used "raid" with proper conjugations. Another linguistic peculiarity is the consonant " $j$ " which gives a visually powerful and slang-like intonation for the word, as in the Finnish language the written form of words corresponds to the way it is pronounced (Ojutkangas et al., 2009). Some of the interviewed players interpreted this as an intentional attempt to manipulate the language or even claim an elevated unique status among the player community, again linking the findings back to social identity. The idea that "jym" was a fabricated or unnecessary addition to Finnish was exemplified by, for example, the following comments:

We already had a good term for gyms.

The word jym means nothing! I could as well start using a new word for a football field with my friends.

As common language is an enabler of communication and cooperation, choosing to use new terminology can be viewed as subscribing to a new social identity. This can manifest as a sense of detachment from the community (Ochs, 1993). Thus, players using foreign terminology are more likely to be viewed as out-group members. This is one mechanism through which language use may reinforce a division between player subgroups.

4.3.3 "Jym" was included in the names of in-game objects. The third reason for the birth of negative attitudes, and for some a reason for sustaining them, was that starting from as early as 2018, "jym" was included in portal candidate submissions (Tregel et al., 2017) made for the Ingress and Pokémon GO. Contrary to the first two given reasons, this theme related to conflict between Pokémon and Ingress players as one of our participants explains:

Bringing the "jym" word to the Niantic OPR [Operation portal reckon - the Ingress PoI peer review system] was polarising, but not between Pokémon teams. While Pokémon bets teams against each other, similar conflict is present between Pokémon players and Ingress players.

Before the Niantic PoI candidate submission and evaluation system came to be known as Niantic Wayfarer in late 2019, Ingress players were in charge of peer reviewing portal candidates, which made "jym" known in the Ingress community. Subsequently, its use was not perceived in a positive light by the interviewed Ingress players and was commonly attributed to drive the PoI database to favouring Pokémon GO players over Ingress players. One of the interviewed participants states the following:

Planting "jym" to OPR included it to not only Pokémon GO, but to Ingress as well. This is an unauthorised entry to territory where Pokémon-specific slang has no place.

One accepted portal submission called "jym" appeared in Southern Finland, and was a gym in Pokémon GO. This portal/gym in question was later renamed to "Puujärven ulkokuntosali" ("Outdoors Workout Gym of Puujärvi”), a more accurate description with proper Finnish grammar. The renaming of "jym" portals in Ingress can be regarded as evidence of the players' collective rejection of the term, as portal name edits are peer-reviewed by the community. The observed discussions about "jym" in the current study (see Table 3) also show many perceived the slang-word as a joke or as an insult. In addition, Ingress rules forbid references to real names, faction names, group names etc. in portal titles. Therefore, "jym" as associated with Pokémon GO, was perceived as a violation of these rules by some players. 
4.3.4 Participants who deviated from the majority. A few counter-intuitive behavioural patterns were observed when comparing content between the chat and survey materials. A team Instinct member was found to have used the word 176 times in a chat, but counterintuitively, stated a negative attitude towards the word. When interviewed, the person explained the following:

I use the word because others use it in many situations quite often. So it's a slang word used in Telegram and that's why I've started using it myself. However, the best term for gym in my opinion is the Finnish word "sali".

Other outliers were team Valor members who had a positive attitude towards the word. When exploring the reasons for this, it was discovered that the majority of them belonged to Enlightened in Ingress. Thus, it is likely they received positive influence towards the word from socialising with users in those circles. One team Valor member replying to have a positive attitude towards "jym" was discovered to have changed their team to Mystic later on, stating having more friends in the team as a reason for the switch. This finding would imply that language use could be a stronger predictor of social circles than the artificially divided teams in the case LBGs.

\section{Discussion}

\subsection{Key findings}

We summarise our most important findings as follows. First, distinct linguistic subcultures emerged among Pokémon GO teams as evidenced by chat data analysis. Second, the players' team in Pokémon GO and Ingress correlated with the use of and attitude towards "jym". Third, three main reasons were associated with a negative attitude towards "jym": (1) "jym" was associated with a certain group of active players. This caused prejudice towards the word, which was further enhanced by how (2) "jym” was often used with improper grammar. The existing negative attitudes were escalated when players started (3) using the slang-term in PoI submissions for the Niantic games.

\subsection{Theoretical implications}

Our study has theoretical implications on the literature on technology-induced polarisation, on language acquisition and game slang and on research on LBGs.

First with regards to group polarisation, we showed that the social identity theory provides a promising framework for understanding technology-induced polarisation in the context of LBGs. We found the case games to direct players to perceive their teammates as their in-group members and the opposing teams as out-group members. Chang and Goodman (2006) argue that LBG players can to some degree exclude themselves from social norms when they are playing by, for instance, wearing clothing that clearly indicates they are playing. However, in modern LBGs where playing is incorporated as part of everyday life, the powerful norms of the real-world guide behaviour (Chang and Goodman, 2006). Despite this, we recorded polarised attitudes towards game slang among players, suggesting that social norms do not at least entirely dampen the polarising effect of games. Consequently, our findings indicate that game design can be used to influence group polarisation. Game mechanics imposing a static team vs team conflict reinforces "us vs them" thinking, whereas based on the intergroup contact hypothesis (Allport, 1954), cooperative activities (such as raids in Pokémon GO (Bhattacharya et al., 2019)) can bring people together and dampen the polarisation effect. These findings are supported by similar results in the context of hobbies and sports events (Ricatti and Klugman, 2013).

Second, we contribute to the research on social media induced polarisation (Conover et al., 2011; Lee et al., 2014; Quershi et al., 2020), by demonstrating that language use and preference can be used to identify underlying polarisation. While previous research has already 
INTR 31,5

suggested that language is a manifestation of group identity (Ksiazek and Webster, 2008), we showed that this division may be particularly strong with new words and slang terms. We also highlight a linguistic issue that languages with few native speakers (e.g. Finnish) are facing: Finnish speaking people are increasingly using technology that is not localised, and thus, their native tongue is under constant pressure to change as new terminology and technology are introduced and used. Because new words are introduced to the language, there is a time period where not all terms are equally accepted and used. Coupled with the fragmentation of news media and polarisation observed in social media (Quershi et al., 2020), this may introduce challenges to communication within societies.

Finally, we contribute to the literature on LBGs by showing that static teams can cause inter-team conflict that carries over from the game to the real world and even language preference. While recent work on the topic has highlighted the importance of cooperative game mechanics for the development of altruism and we-intentions (Riar et al., 2020), our study shows that the static teams also have a polarising effect.

\subsection{Practical implications}

One of the primary implications to practice of our research is to LBG design. Arguably Pokémon GO, perhaps unintentionally, first caused and then fixed a group polarisation problem. Back in 2016, the static teams were fighting against each other over territory and there were few cooperation opportunities between teams (Laato et al., 2021). This was changed in 2017 with the introduction of raids where players from all teams come together to defeat a common strong foe (Bhattacharya et al., 2019; Laato et al., 2021). Raids could unite players under a common cause and help them feel empathy towards each other. Building off the intergroup contact hypothesis (Allport, 1954), as a remedy for reducing group polarisation, in-game cooperation opportunities between teams/factions should be implemented. As mentioned, Pokémon GO already made changes to reduce polarisation, but Ingress remains a game where factions cannot cooperate. While the game mechanics of Ingress do not allow cross-team cooperation, significant cooperative benefits have been reported from playing the game (Morschheuser et al., 2017; Riar et al., 2020; Söbke et al., 2017). This would suggest that practitioners and game designers may leverage group identity and polarisation to engage players with members of their own team and even scaffold social connectivity, which is one of the reported main benefits of playing LBGs (Finco, 2019; Humphreys, 2017; Kaczmarek et al., 2017; Paasovaara et al., 2017; Vella et al., 2019).

Our study also has practical implications on strategies to curb technology induced polarisation. In our study context we could pinpoint the birth of polarisation to the static teams. As polarisation is at least partially caused by a purely artificial division, alternative artificial divisions (i.e. "recategorisation") and meetings between people where they are sorted into new social subgroups shows promise as an intervention strategy. As the human social circles are largely influenced by their socioeconomic status, a hobby where people from various backgrounds can get together and unite against a strong enemy can be effective in reducing polarisation in other areas of life (e.g. ideological, political, religious).

Finally, the COVID-19 pandemic brought light to the importance of social interaction for learning, and the learning of social skills at schools. As school buildings closed and countries adopted distance education solutions, the implicitly present social benefits of school suddenly diminished. Our findings bring a new perspective to the discussion of using LBGs for social education. Based on the results, it can be proposed to use LBGs to teach living in a globalised world and help self-identify own prejudiced attitudes. The process of forming negative attitudes towards other players, and then meeting them in raids and forming a relationship 
with them, delivers an empirical experience regarding the inaccuracy of the human natural tendency to view people with prejudice.

\subsection{Limitations}

The audience from whom data was collected were exclusively from South-Western Finland. The authors were themselves active participants in the analysed communities, with presence in all three Pokémon GO teams and both Ingress factions. Despite the birth of "jym" being natural, some of the authors participated in using, discussing and criticising the word among the participants. This occurred naturally before data was collected for the current study. Reportedly some players refused to answer the questionnaire concerning the "jym"-word, as they had negative feelings towards the word, possibly resulting in a positive bias in favour of the word in our results. Furthermore, the prominent presence of the authors in both gaming communities may have influenced consciously or unconsciously the participants' survey responses and interview replies. However, as all teams and factions were represented and surveys were anonymised, we expect this effect to be minimal. The participants in the survey were self-selected, and the number of interview participants was limited by their willingness and availability. One additional limitation concerns the fidelity of the collected survey data. For example, we asked participants to select a discrete age group as opposed to precise age. This may have resulted in slight reduction of statistical power in identifying age-related associations and hence, our findings involving age may have missed subtle associations that would have required an exact age. However, we expect this to have had a minimal effect, as reasonably justified discrete group representation of continuous data in many cases adequately represents the original variable in behavioural sciences (Kim and Frisby, 2019).

Our data analysis focused on observing slang word use to identify differences between player subgroups. While language can be a powerful indicator of social status and group identity, it entails more than just terminology (Ksiazek and Webster, 2008; Rumsey, 1990). As the study was limited geographically and linguistically to South-Western Finland and the Finnish language, its interpretability may exhibit characteristics specific for the Finno-Ugric language tree and the Finnish culture. While "jym" was accepted by some subgroups and rejected by others, the interviews revealed several reasons for this, one of which was its use with improper Finnish grammar. This hints that there are language specific complex nuances in communication and calls for more detailed analysis of phrasing, grammar and even tone to uncover social identities of players using the linguistic ideology approach (Rumsey, 1990). Besides written communication, "jym" was used and discussed face-to-face while playing, and these discussions were not recorded. This limited us from fully exploring the evolution of the word.

\section{Conclusions and future work}

We observed the effect of divisive static teams on players' social behaviour via linguistic data collected in multiple layers. With this unique empirical study design, we identified trends in game slang use specific to teams and possibly further inner subgroups inside teams. A subsequent survey and interviews focusing on a particular word, "jym", demonstrated systematically that attitudes towards certain language and slang terms were associated with the players' chosen in-game team. These exploratory findings on technology induced polarisation in the context of LBGs open several future research directions.

With regards to language and slang in LBGs and multiplayer online games, future studies should focus on expanding outside the geographical and linguistic boundaries of individual countries and generalise language evolution in games in a broader context. In the case of using language as a vessel for identifying group polarisation, other approaches besides 
INTR 31,5

looking at individual words should be harnessed. For example, our interviews revealed that proper grammar use played an important role in adapting or discarding novel game related terminology. Furthermore, because LBGs simultaneously incorporate in-game communication as well as real world communication in person, future work on language acquisition, polarisation and LBGs could further explore the complex interplay between these two dimensions.

As the contact hypothesis (Allport, 1954) suggests meaningful interaction on equal standing between two opposing groups can lead to diminished prejudice, future research could complement our findings by focusing on intervention strategies for reducing polarisation with inter-team cooperative endeavours. Furthermore, social personality and self-efficacy play a role in group polarisation (Satherley et al., 2020). Thus, exploring individual traits and their relationship in online gamers and LBG players presents a venue for identifying vulnerable - or resistant - personality types. By better characterising such individualistic behaviour, future game design may be better equipped to alleviate trigger-like effects from mechanics or communication mediums that adversely affect certain player sub-populations. While our work successfully identified interesting patterns in opposing out-group social strata, further work in this field is warranted, as previous research on, e.g. Ingress has mainly focused on the benefits of cooperation (Morschheuser et al., 2017; Riar et al., 2020) rather than negative outcomes.

In summary, the issues and effects presented and discussed above reach far beyond the scope of LBGs and Finno-Ugric languages. LBGs are merely a single application domain where technology induced social phenomena arise. Our current work provides a foundation for future extensions on this research topic by re-vitalising the idea to use language as an indicator of polarisation (Irvine et al., 2009; Ksiazek and Webster, 2008; Rumsey, 1990). As technology-mediated social stratification naturally arises in situations beyond LBGs, increasing our collective understanding of mechanisms driving negative conflict-prone attitudes has great potential for improving social and individual well-being.

\section{ORCID iDs}

Samuli Laato Dhttp://orcid.org/0000-0003-4285-0073

Teemu Daniel Laajala Dhttp://orcid.org/0000-0002-7016-7354

\section{References}

Abrams, D. and Hogg, M.A. (1988), "Comments on the motivational status of self-esteem in social identity and intergroup discrimination”, European Journal of Social Psychology, Vol. 18 No. 4, pp. 317-334, doi: 10.1002/ejsp.2420180403.

Ackermann, J. (2012), "Playing computer games as social interaction: an analysis of LAN parties", in Fromme, J. and Unger, A. (Eds), Computer Games and New Media Cultures, Springer, Dordrecht, pp. 465-476, doi: 10.1007/978-94-007-2777-9_29.

Allport, G.W. (1954), The Nature of Prejudice, Addison-Wesley, Reading, MA.

Bagby, R.M. and Rector, N.A. (1992), "Prejudice in a simulated legal context: a further application of social identity theory", European Journal of Social Psychology, Vol. 22 No. 4, pp. 397-406, doi: 10. 1002/ejsp.2420220408.

Beer, J.S., Chester, D.S. and Hughes, B.L. (2013), "Social threat and cognitive load magnify selfenhancement and attenuate self-deprecation", Journal of Experimental Social Psychology, Vol. 49 No. 4, pp. 706-711, doi: 10.1016/j.jesp.2013.02.017.

Bhattacharya, A., Windleharth, T.W., Ishii, R.A., Acevedo, I.M., Aragon, C.R., Kientz, J.A., Yip, J.C. and Lee, J.H. (2019), "Group interactions in location-based gaming: a case study of raiding in 
Pokémon GO", Proceedings of the 2019 CHI Conference on Human Factors in Computing Systems, pp. 1-12, doi: 10.1145/3290605.3300817.

Blackburn, J. and Kwak, H. (2014), "STFU NOOB! Predicting crowdsourced decisions on toxic behaviour in online games", Proceedings of the 23rd International Conference on World wide web, pp. 877-888, doi: 10.1145/2566486.2567987.

Brewer, M.B. (1999), “The psychology of prejudice: in-group love and out-group hate?", Journal of Social Issues, Vol. 55 No. 3, pp. 429-444, doi: 10.1111/0022-4537.00126.

Brewer, M.B., Caporael, L.R., Brown, R. and Capozza, D. (2006), "Social identity motives in evolutionary perspective”, Social Identities: Motivational, Emotional, Cultural Influences, pp. 135-152, Psychology Press.

Burgess, S.R., Stermer, S.P. and Burgess, M.C. (2012), "Video game playing and academic performance in college”, College Student Journal, Vol. 462, pp. 376-388.

Chang, M. and Goodman, E. (2006), “Asphalt games: enacting place through locative media”, Leonardo Electronic Almanac, Vol. 14 No. 3, available at: http://www.leoalmanac.org/wp-content/uploads/ 2012/07/Asphalt-Games-Enacting-Place-Through-Locative-Media-Vol-14-No-3-July-2006Leonardo-Electronic-Almanac.pdf (accessed 5 December 2020).

Cheung, C.M., Chiu, P.Y. and Lee, M.K. (2011), "Online social networks: why do students use Facebook?”, Computers in Human Behaviour, Vol. 27 No. 4, pp. 1337-1343, doi: 10.1016/j.chb. 2010.07.028.

Cichocka, A., Dhont, K., Makwana, A.P. and Back, M. (2017), "On self-love and out-group hate: opposite effects of narcissism on prejudice via social dominance orientation and right-wing authoritarianism”, European Journal of Personality, Vol. 31 No. 4, pp. 366-384, doi: 10.1002/ per.2114.

Coleman, J. (2012), The Life of Slang, Oxford University Press, Oxford.

Conover, M., Ratkiewicz, J., Francisco, M., Gonçalves, B., Menczer, F. and Flammini, A. (2011), "Political polarization on twitter", Proceedings of the International AAAI Conference on Web and Social Media, Vol. 5 No. 1, available at: https://ojs.aaai.org/index.php/ICWSM/article/view/ 14126 (accessed 28 January 2021).

Drake, G.F. (1980), "The social role of slang”, in Giles, H., Robinson, P. and Smith, P.M. (Eds), Language Social Psychological Perspectives, Elsevier, New York, NY, pp. 63-70.

Eble, C.C. (1996), Slang and Sociability: In-Group Language Among College Students, University of North Carolina Press, North Carolina.

Finco, M.D. (2019), "I play, you play and we play together: social interaction through the use of Pokémon GO", in Geroimenko, V. (Ed.), Augmented Reality Games I, Springer International Publishing, pp. 117-128.

Fragoso, S. and Reis, B.M.S. (2016), "Ludic Re-enchantment and the power of locative games: a case study of the game Ingress", Proceedings of the International conference on culture, technology, and communication, Cham, Springer, pp. 131-148, doi: 10.1007/978-3-319-50109-3_9.

Gu, Z., Eils, R. and Schlesner, M. (2016), "Complex heatmaps reveal patterns and correlations in multidimensional genomic data”, Bioinformatics, Vol. 32 No. 18, pp. 2847-2849, doi: 10.1093/ bioinformatics/btw313.

Hamari, J. (2019), "Gamification", in Ritzer, G. and Rojek, C. (Eds), The Blackwell Encyclopedia of Sociology, John Wiley \& Sons, New York, NY, doi: 10.1002/9781405165518. wbeos1321.

Hamari, J. and Koivisto, J. (2015), “Working out for likes': an empirical study on social influence in exercise gamification", Computers in Human behaviour, Vol. 50, pp. 333-347, doi: 10.1016/j.chb. 2015.04.018.

Harris, M.A. and Orth, U. (2020), "The link between self-esteem and social relationships: a metaanalysis of longitudinal studies", Journal of Personality and Social Psychology, Vol. 119 No. 6, p. 1459, doi: $10.1037 / \mathrm{pspp} 0000265$.

\section{Group polarisation}


INTR 31,5

Hogg, M.A. (2016), "Social identity theory", in McKeown, S., Haji, R. and Ferguson, N. (Eds), Understanding Peace and Conflict through Social Identity Theory. Peace Psychology Book Series, Springer, Cham, doi: 10.1007/978-3-319-29869-6_1.

Humphreys, L. (2017), "Involvement shield or social catalyst: thoughts on sociospatial practice of Pokémon GO", Mobile Media and Communication, Vol. 5 No. 1, pp. 15-19, doi: 10.1177/ 2050157916677864.

Irvine, J.T., Gal, S. and Kroskrity, P.V. (2009), "Language ideology and linguistic differentiation", in Duranti, A. (Ed.), Linguistic Anthropology: A Reader, Wiley and Sons, West Sussex, Vol. 1, pp. $402-434$.

Jetten, J., Spears, R. and Manstead, A.S. (1996), "Intergroup norms and intergroup discrimination: distinctive self-categorization and social identity effects", Journal of Personality and Social Psychology, Vol. 71 No. 6, pp. 1222-1233, doi: 10.1037/0022-3514.71.6.1222.

Kaczmarek, L.D., Misiak, M., Behnke, M., Dziekan, M. and Guzik, P. (2017), "The Pikachu effect: social and health gaming motivations lead to greater benefits of Pokémon GO use", Computers in Human behaviour, Vol. 75, pp. 356-363, doi: 10.1016/j.chb.2017.05.031.

Kelman, H.C. (1958), "Compliance, identification, and internalization: three processes of attitude change", Journal of Conflict Resolution, Vol. 2 No. 1, pp. 51-60.

Kim, S.K. and Frisby, C.L. (2019), "Gaining from discretization of continuous data: the correspondence analysis biplot approach”, Behaviour Research Methods, Vol. 51 No. 2, pp. 589-601, doi: 10.3758/ s13428-018-1161-1.

Kircher, R. and Fox, S. (2019), "Attitudes towards Multicultural London English: implications for attitude theory and language planning", Journal of Multilingual and Multicultural Development, Vol. 40 No. 10, pp. 847-864, doi: 10.1080/01434632.2019.1577869.

Kordyaka, B., Klesel, M. and Jahn, K. (2019), "Perpetrators in League of Legends: scale development and validation of toxic behaviour", Proceedings of the 52nd Hawaii International Conference on System Sciences, doi: 10.24251/HICSS.2019.299.

Ksiazek, T.B. and Webster, J.G. (2008), "Cultural proximity and audience behaviour: the role of language in patterns of polarization and multicultural fluency", Journal of Broadcasting and Electronic Media, Vol. 52 No. 3, pp. 485-503, doi: 10.1080/08838150802205876.

Kwak, H., Blackburn, J. and Han, S. (2015), "Exploring cyberbullying and other toxic behaviour in team competition online games", Proceedings of the 33rd Annual ACM Conference on Human Factors in Computing Systems, pp. 3739-3748, doi: 10.1145/2702123.2702529.

Laato, S., Pietarinen, T., Rauti, S. and Laine, T.H. (2019), "Analysis of the quality of points of interest in the most popular location-based games", Proceedings of the 20th International Conference on Computer Systems and Technologies, pp. 153-160, doi: 10.1145/3345252.3345286.

Laato, S., Inaba, N. and Paloheimo, M. (2020a), "The effect of team choice in Ingress and Pokémon GO for players' social circles and attitudes towards game slang", Proceedings of the 53rd Hawaii International Conference on System Sciences, doi: 10.24251/HICSS.2020.324.

Laato, S., Pietarinen, T., Rauti, S. and Sutinen, E. (2020b), "Potential benefits of playing location-based games: an analysis of game mechanics", in Lane, H.C., Zvacek, S. and Uhomoibhi, J. (Eds), Computer Supported Education 2019, Communications in Computer and Information Science, Springer, Cham, Vol. 1220, doi: 10.1007/978-3-030-58459-7_27.

Laato, S., Kordyaka, B., Islam, A.K.M. and Papangelis, K. (2021), "Landlords of the digital world: how territoriality and social identity predict playing intensity in location-based games", Proceedings of the 54th Hawaii International Conference on System Sciences, doi: 10.24251/HICSS.2021.091.

Lee, J.K., Choi, J., Kim, C. and Kim, Y. (2014), "Social media, network heterogeneity, and opinion polarization", Journal of Communication, Vol. 64 No. 4, pp. 702-722, doi: 10.1111/jcom.12077.

Leorke, D. (2018), Location-based Gaming: Play in Public Space, Springer, Singapore. 
Liao, G.Y., Pham, T.T.L., Cheng, T.C.E. and Teng, C.I. (2020), "How online gamers' participation fosters their team commitment: perspective of social identity theory", International Journal of Information Management, Vol. 52, doi: 10.1016/j.ijinfomgt.2020.102095.

Liberati, N. (2019), "Mediation theory between pokémon GO and the everyday world", Augmented Reality Games I, Springer, Cham, pp. 51-60, doi: 10.1007/978-3-030-15616-9_4.

Löfberg, L., Archer, D., Piao, S., Rayson, P., McEnery, T., Varantola, K. and Juntunen, J.P. (2003), "Porting an English semantic tagger to the Finnish language", Proceedings of the Corpus Linguistics 2003 Conference, pp. 457-464.

Locksley, A., Ortiz, V. and Hepburn, C. (1980), "Social categorization and discriminatory behaviour: extinguishing the minimal intergroup discrimination effect", Journal of Personality and Social Psychology, Vol. 39 No. 5, p. 773, doi: 10.1037/0022-3514.39.5.773.

Mackie, D.M. (1986), "Social identification effects in group polarization", Journal of Personality and Social Psychology, Vol. 50 No. 4, p. 720, doi: 10.1037/0022-3514.50.4.720.

Maddox, G.B., Naveh-Benjamin, M., Old, S. and Kilb, A. (2012), "The role of attention in the associative binding of emotionally arousing words", Psychonomic Bulletin and Review, Vol. 19 No. 6, pp. 1128-1134, doi: 10.3758/s13423-012-0315-x.

Morschheuser, B., Riar, M., Hamari, J. and Maedche, A. (2017), "How games induce cooperation? A study on the relationship between game features and we-intentions in an augmented reality game", Computers in Human Behaviour, Vol. 77, pp. 169-183, doi: 10.1016/j.chb.2017. 08.026 .

Niantic (2019), "Make way for friends, trading and gifting in Pokémon GO", Niantic, available at: https://pokemongolive.com/en/post/friendsandtrading/ (accessed 5 February 2021).

Ochs, E. (1993), "Constructing social identity: a language socialization perspective", Research on Language and Social Interaction, Vol. 26 No. 3, pp. 287-306, doi: 10.1207/s15327973rlsi2603_3.

Ojutkangas, K., Larjavaara, M., Miestamo, M. and Ylikoski, J. (2009), Johdatus kielitieteeseen, WSOY oppimateriaalit, Helsinki.

Olejniczak, J. (2015), “A linguistic study of language variety used on Twitch.tv: descriptive and corpusbased approaches”, Redefining Community in Intercultural Context, Vol. 4 No. 1, pp. 329-334.

Paasovaara, S., Jarusriboonchai, P. and Olsson, T. (2017), "Understanding collocated social interaction between Pokémon GO players”, Proceedings of the 16th International Conference on Mobile and Ubiquitous Multimedia, pp. 151-163, doi: 10.1145/3152832.3152854.

Peirce, B.N. (1995), “Social identity, investment, and language learning”, Tesol Quarterly, Vol. 29 No. 1, pp. 9-31, doi: 10.2307/3587803.

Porter, S.C., Rheinschmidt-Same, M. and Richeson, J.A. (2016), "Inferring identity from language: linguistic intergroup bias informs social categorization", Psychological Science, Vol. 27 No. 1, pp. 94-102, doi: 10.1177/0956797615612202.

Potts, R. and Yee, L. (2019), "Pokémon GO-ing or staying: exploring the effect of age and gender on augmented reality game player experiences in public spaces”, Journal of Urban Design, Vol. 24 No. 6, pp. 878-895.

Quershi, I., Bhatt, B., Gupta, S. and Tiwari, A.A. (2020), "Call for papers: causes, symptoms and consequences of social media induced polarization (SMIP)", Information Systems Journal, available at: https://onlinelibrary.wiley.com/pbassets/assets/13652575/ISJ_SMIP_ CFP1586861685850.pdf (accessed 5 February 2021).

R Core Team (2020), R: A Language and Environment for Statistical Computing, R Foundation for Statistical Computing, Vienna.

Riar, M., Morschheuser, B., Hamari, J. and Zarnekow, R. (2020), "How game features give rise to altruism and collective action? Implications for cultivating cooperation by gamification", Proceedings of the 53rd Hawaii International Conference on System Sciences, doi: 10.24251/ HICSS.2020.086. 
INTR 31,5

Ricatti, F. and Klugman, M. (2013), “Connected to something': soccer and the transnational passions, memories and communities of sydney's Italian migrants", The International Journal of the History of Sport, Vol. 30 No. 5, pp. 469-483, doi: 10.1080/09523367.2013.77073.

Rumsey, A. (1990), "Wording, meaning, and linguistic ideology", American Anthropologist, Vol. 92 No. 2, pp. 346-361, doi: 10.1525/aa.1990.92.2.02a00060.

Saker, M. and Evans, L. (2021), "Introduction: locative games and intergenerational play", Intergenerational Locative Play, Emerald Publishing, pp. 1-22, doi: 10.1108/978-1-83909-139120211004.

Satherley, N., Sibley, C.G. and Osborne, D. (2020), "Identity, ideology, and personality: examining moderators of affective polarization in New Zealand", Journal of Research in Personality, Vol. 87, p. 103961, doi: 10.1016/j.jrp.2020.103961.

Schiano, D.J., Nardi, B., Debeauvais, T., Ducheneaut, N. and Yee, N. (2011), "A new look at World of Warcraft's social landscape", Proceedings of the 6th International Conference on Foundations of Digital Games, pp. 174-179, doi: 10.1145/2159365.2159389.

Sheng, L.Y. (2013), "Modelling learning from Ingress (Google's augmented reality social game)", 2013 IEEE 63rd Annual Conference International Council for Education Media, pp. 1-8, doi: 10.1109/ CICEM.2013.6820152.

Shirai, A., Kose, Y., Minobe, K. and Kimura, T. (2015), "Gamification and construction of virtual field museum by using augmented reality game 'Ingress", Proceedings of the 2015 Virtual Reality International Conference, pp. 1-4, doi: 10.1145/2806173.2806182.

Sia, C.L., Tan, B.C. and Wei, K.K. (2002), "Group polarization and computer-mediated communication: effects of communication cues, social presence, and anonymity", Information Systems Research, Vol. 13 No. 1, pp. 70-90, doi: 10.1287/isre.13.1.70.92.

Söbke, H., Hauge, J.B. and Stefan, I.A. (2017), "Prime example ingress reframing the pervasive game design framework (PGDF)", International Journal of Serious Games, Vol. 4 No. 2, doi: 10.17083/ijsg.v4i2.182.

Suler, J. (2004), "The online disinhibition effect", Cyberpsychology and behaviour, Vol. 7 No. 3, pp. 321-326, doi: 10.1089/1094931041291295.

Sunstein, C.R. (1999), “The law of group polarization”, University of Chicago Law School, John M. Olin Law \& Economics Working Paper, doi: 10.2139/ssrn.199668.

Tajfel, H. (1970), "Experiments in intergroup discrimination”, Scientific American, Vol. 223 No. 5, pp. 96-103.

Tajfel, H. (1974), "Social identity and intergroup behaviour”, Social Science Information, Vol. 13 No. 2, pp. 65-93.

Tokgöz, C. and Polat, B. (2018), "Sociability on location based mobile games: an ethnographic research on pokémon GO and ingress in istanbul", European Journal of Social Science Education and Research, Vol. 5 No. 1, pp. 111-120.

Tregel, T., Raymann, L., Göbel, S. and Steinmetz, R. (2017), "Geodata classification for automatic content creation in location-based games", Joint International Conference on Serious Games, Cham, Springer, pp. 212-223, doi: 10.1007/978-3-319-70111-0_20.

Uhlmann, E.L., Brescoll, V.L. and Paluck, E.L. (2006), “Are members of low status groups perceived as bad, or badly off? Egalitarian negative associations and automatic prejudice", Journal of Experimental Social Psychology, Vol. 42 No. 4, pp. 491-499, doi: 10.1016/j.jesp.2004.10.003.

Vaterlaus, J.M., Frantz, K. and Robecker, T. (2019), "Reliving my childhood dream of being a Pokémon trainer: an exploratory study of college student uses and gratifications related to Pokémon GO", International Journal of Human-Computer Interaction, Vol. 35 No. 7, pp. 596-604, doi: 10.1080/ 10447318.2018.1480911.

Vella, K., Johnson, D., Cheng, V.W.S., Davenport, T., Mitchell, J., Klarkowski, M. and Phillips, C. (2019), "A sense of belonging: pokémon GO and social connectedness", Games and Culture, Vol. 14 No. 6, pp. 583-603, doi: 10.1177/1555412017719973. 
Wiens, K. (2012), "I won't hire people who use poor grammar. here's why”, available at: https://www.yu. edu/sites/default/files/legacy/uploadedFiles/Jewish_Living_and_Learning/Center_for_the_ Jewish_Future/Community_Resources/ChampionsGate/Program/I\%20Won't \%20Hire\%20People \%20Who\%20Use\%20Poor\%20Grammar.\%20Here's\%20Why.pdf (accessed 5 February 2021).

Williams, D., Ducheneaut, N., Xiong, L., Zhang, Y., Yee, N. and Nickell, E. (2006), "From tree house to barracks: the social life of guilds in World of Warcraft", Games and Culture, Vol. 1 No. 4, pp. 338-361, doi: 10.1177/1555412006292616.

Wright, R. and Jacobs, J.A. (1994), "Male flight from computer work: a new look at occupational resegregation and ghettoization”, American Sociological Review, Vol. 59 No. 4, pp. 511-536.

\section{Supplementary}

The supplementary file is available online for this article.

\section{Corresponding author}

Samuli Laato can be contacted at: sadala@utu.fi

For instructions on how to order reprints of this article, please visit our website: 